\title{
Patterns of venom synthesis and use in the fire ant, Solenopsis invicta
}

\author{
Kevin L. Haight*, Walter R. Tschinkel \\ Department of Biological Science, Florida State University, Tallahassee, FL 32306-4370, USA
}

Received 19 March 2003; accepted 9 September 2003

\begin{abstract}
In the life of the fire ant, Solenopsis invicta, venom plays several important roles, including prey capture, defense, and antimicrobial action. Although this venom's chemistry, pharmacology, and effects on humans have been extensively studied, its patterns of synthesis and use have not. We determined the ability of different-aged workers to synthesize venom, and measured the amount of venom workers delivered per sting. Newly eclosed workers contained little or no venom in their reservoirs. The rate of synthesis was highest in workers aged 1 day after adult eclosion $(1.17 \mu \mathrm{g}$ venom/day for workers with headwidths of $1 \mathrm{~mm})$, declined by $75 \%$ in workers aged 15 days $(0.30 \mu \mathrm{g}$ venom/day), and was negligible thereafter. Inducing ants to sting dummies as surrogates for humans, workers were found to deliver an average of $0.66 \mathrm{nl}$ per sting, amounting to $3.1 \%$ of the average individual venom supply. Older workers (foragers) delivered less venom per sting than mid-age workers (reserves) and venom dose from nest-defenders was 55\% higher in the spring than in the rest of the year. Thus, fire ant venom synthesis is limited to early life, and injected venom dose appears to be modulated. Economic explanations for the observed venom-use patterns are discussed.
\end{abstract}

(C) 2003 Elsevier Ltd. All rights reserved.

Keywords: Fire ant; Solenopsis invicta; Defense; Venom production; Stings; Venom dose; Venom milking; Season; Solenopsins

\section{Introduction}

Many organisms use venom for subduing prey and/or for defense. Because survival depends on an organism's ability to feed and defend itself effectively, venom is of great importance to those organisms that rely on it to meet these needs. In social organisms, e.g. many aculeate Hymenoptera, venom can be considered at two levels: colony and individual. At the colony level, sufficient venom must be available to meet the colony's needs without undue sacrifice of other functions such as growth and reproduction. These needs are parceled out to the individual workers, who must be able to generate, store, and deliver enough venom to be individually effective, without reducing their overall usefulness to the colony in other areas. For instance,

\footnotetext{
* Corresponding author. Tel.: + 1-850-644-9811; fax: + 1-850644-0481.

E-mail address: haight@bio.fsu.edu (K.L. Haight).
}

workers that expend too much venom obtaining prey may not be left with sufficient venom to be useful nest defenders, potentially putting the colony at increased risk until it can restore effective venom levels. Determining how ants balance these needs requires knowledge of the physiological capacity to produce venom (gland competence and synthesis rate) and the increments in which it is used (venom dose). These factors have not been fully assessed in the fire ant, Solenopsis invicta Buren (Hymenoptera:Formicidae), despite its aggressive stinging behavior and common envenomation of humans (Clemmer and Serfling, 1975; Adams and Lofgren, 1981; Adams and Lofgren, 1982).

Human reactions to $S$. invicta's stings vary widely and may include the formation of characteristic sterile pustules, urticaria, edema, dermal necrosis, and in rare cases anaphylactic shock and death (deShazo et al., 1984; Stablein and Lockey, 1987; Rhoades et al., 1989). The venom responsible for these reactions is a mixture of 2-methyl 6-alkyl or alkenyl disubstituted piperidines, 
dubbed solenopsins, and a small amount (approximately $0.1 \%$ by weight) of protein (MacConnell et al., 1971; Baer et al., 1979; Deslippe and Guo, 2000). The protein components are allergenic, and the solenopsins possess cytotoxic, insecticidal, antibiotic, and antimycotic properties (Caro et al., 1957; Blum et al., 1958; Adrouny et al., 1959; Blum and Callahan, 1960; Jung et al., 1963; Bhatkar et al., 1972; Jouvenaz et al., 1972; Read et al., 1978; Baer et al., 1979; Lind, 1982; Blum, 1988; Storey et al., 1991).

Whereas $S$. invicta's venom has been the focus of many studies, its production and use have received relatively little attention beyond determination of the chemical nature of its biosynthesis (Leclercq et al., 1996) and the contexts of its use: prey capture (Hays and Hays, 1959; Blum and Callahan, 1960; Vinson and Sorenson, 1986; Lockley, 1995) and defense in response to disturbance (Blum, 1984; Vinson and Sorenson, 1986), competitors (Bhatkar et al., 1972; Obin and Vander Meer, 1985), and pathogens (Obin and Vander Meer, 1985). As a result, basic venom-related physiological and behavioral questions have remained largely unanswered. For instance, it is unknown whether fire ants possess the ability (gland competence) to synthesize venom throughout their lives, or if synthesis is limited to a portion thereof. The rate at which workers produce (and potentially replace) venom is also unknown, as is the amount they deliver per sting, and how, if at all, this venom dose varies. Dose variation is likely to be related to effectiveness, because the degree of pain and cell/tissue damage caused by fire ant venom is dose-dependent (Read et al., 1978).

This investigation consists of two parts, a venom synthesis experiment and three venom-use studies. In the synthesis experiment, de novo venom synthesis is assessed in venom-depleted workers across a range of ages. In the venom-use studies, the amount of venom delivered per sting by $S$. invicta workers during defense against human disturbance is quantified, and its variation depending on venom availability (individual venom supply), worker age, worker size, and season is investigated.

\section{Materials and methods}

\subsection{Venom synthesis experiment}

Eight even-aged worker cohorts were established between August 2000 and February 2001 using pupae from a total of 132 colonies collected from the Tallahassee, FL area. Each cohort was created by placing late-stage worker pupae from a minimum of 5 different colonies into an 'eclosion tray' with a number of small, adult workers (headwidths $\leq 0.60 \mathrm{~mm}$ ) to help them eclose (Lamon and Topoff, 1985) (all trays had Fluon-coated sides to prevent ants from escaping; Fluon- Northern Products Inc., Woonsocket, RI). A moist, plaster-floored, darkened petri dish nest, along with fresh water and sugar water $(20 \% \mathrm{v} / \mathrm{v})$ in cotton-plugged test tubes, was provided for each cohort. Eclosion trays were kept under constant temperature $\left(30 \pm 2{ }^{\circ} \mathrm{C}\right)$ and light. Twenty-four hours after being placed in an eclosion tray, all newly-eclosed workers (identifiable by their light amber color) were collected from these eclosion trays, resulting in groups of ants all within $24 \mathrm{~h}$ of the same age. These were placed in an 'age tray' and kept as described above, with the ad libidum addition of dead tenebrionid beetle larvae (Zophobus sp.), until they were either $1,15,29,43,57,71,85$, or 99 days old. When they reached their designated age, each group was randomly split into three subgroups: Unmilked, Depleted, and Synthesis. Workers in the unmilked subgroups were simply killed by freezing and stored for later venom quantification (see below). Those in the depleted subgroups were milked (see below) to deplete their venom stores immediately before being frozen. Workers in the synthesis subgroups were also milked, but they were then placed in a 'synthesis tray' (maintained and provisioned like the age trays) for 12 more days (to allow venom synthesis to occur) before being killed and stored for subsequent venom quantification. Stored workers were individually frozen in ice to prevent desiccation.

\subsubsection{Venom quantification}

Worker venom was quantified using a Varian Aerograph Model 1400 gas chromatograph $\left(1 / 8^{\prime \prime} \times 5^{\prime}\right.$ stainless steel column with $5 \%$ OV-101 on HP chromosorb W 80/100 mesh; $\mathrm{N}_{2}: 20 \mathrm{ml} / \mathrm{min}, \mathrm{H}_{2}: 40 \mathrm{ml} / \mathrm{min}$, air: $110 \mathrm{ml} / \mathrm{min}$, oven: $240{ }^{\circ} \mathrm{C}$; flame ionization detector) attached to a Fisher Recordall $^{\mathrm{TM}}$ Series 5000 chart recorder. Each worker's venom sac was removed intact by dissection, placed in a vial, and perforated to release the venom. One hundred $\mu l$ of carbon disulfide $\left(\mathrm{CS}_{2}\right)$ containing $0.05 \mu \mathrm{g} / \mu \mathrm{l}$ of $n$-tetracosane $\left(\mathrm{CH}_{3}\left(\mathrm{CH}_{2}\right)_{22} \mathrm{CH}_{3}\right)$ as an internal standard were added (Storey et al., 1991). A $5 \mu$ l sample, $1 / 20$ of the total (containing $0.25 \mu \mathrm{g}$ standard), was then injected into the chromatograph and the resulting venom peaks were measured $(\mathrm{cm})$ in relation to the internal standard peak (Fig. 1). The amount of venom each peak represented was calculated using the equation $\mu g_{\text {venom }}=\left(\right.$ Peak Height ${ }_{\text {venom }} /$ Peak Height standard $) \times 0.25 \mu \mathrm{g}_{\text {standard }} \times 20$. This yielded the amount $(\mu \mathrm{g})$ of venom each worker contained. Both Vander Meer (1988) and Deslippe and Guo (2000) reported this amount to vary with worker size (i.e. headwidth), therefore, each worker's headwidth was measured using a wedge micrometer (Porter, 1983) and each worker's venom content was divided by the cube of its headwidth. ${ }^{1}$ This yielded the size-standardized response variable, $\mu \mathrm{g} / \mathrm{mm}^{3}$. As a precaution against accidental inclusion of unknown-aged helper

\footnotetext{
${ }^{1}$ Porter and Tschinkel (1985) found worker size, measured by body weight $(\mathrm{mg})$, to vary nearly directly with the cube of worker headwidth $\left(\mathrm{mm}^{3}\right)$.
} 


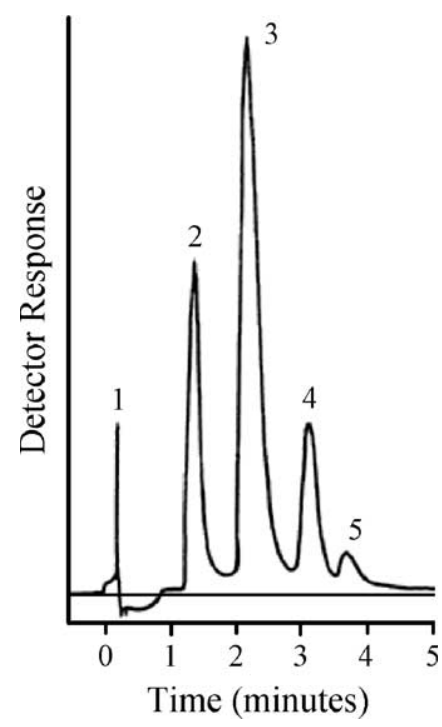

Fig. 1. Chromatogram of $S$. invicta worker venom with $n$ tetracosane internal standard. Individual venom components were not fully resolved in this study (see Deslippe and Guo (2000) for fully resolved chromatogram). Peaks: $1=\mathrm{CS}_{2}$ (solvent); 2, 3, and $5=$ solenopsins; $4=n$-tetracosane $($ standard $)$.

workers in the evenaged cohorts, no workers with headwidths $\leq 0.60 \mathrm{~mm}$ were included in the statistical analyses.

\subsubsection{Venom milking}

Depleted and synthesis workers were milked using a novel method that capitalized on defensive gaster-flagging behavior (Bhatkar et al., 1972; Obin and Vander Meer, 1985) during which venom is exuded from the stinger in response to heterospecific arthropods. The milking apparatus consisted of two strips of paper, the 'mobile gate' and the 'fixed gate', held on edge to a wooden board by clips supported with steel pegs. Both the mobile and fixed gates had a slit on one side leading to a pinhole (see Haight (2002) for schematic). Milking proceeded as follows: a live Florida carpenter ant worker, Camponotus floridanus Buckley, was placed in the fixed gate by sliding its petiole down the slit until it was seated in the pinhole. A S. invicta worker was similarly placed in the mobile gate facing the $C$. floridanus worker. The mobile gate was then moved carefully back and forth to bring the workers into brief contact with one another. Upon contact, the fire ants extruded their stingers and exuded venom, which was absorbed onto filter paper and discarded. This brief contact was repeated over a period of 5 min for each $S$. invicta worker milked.

\subsection{Venom-use studies}

\subsubsection{Sting sampling}

'Sting dummies' were used to sample the amount of venom per sting (venom dose) delivered by individual workers. Sting dummies consisted of notched pieces of $\mathrm{pH}$ paper (pHydrion 150AB, Micro Essential Lab Inc., Brooklyn, NY) with a thin layer, or 'skin', of silicone rubber partially covering one side (see Haight, 2002 for schematic). All sting samples were taken in the field by disturbing colonies via blowing and/or tapping and allowing workers to climb one at a time onto the index finger of a specially textured latex glove (Haight, 2002) to sting. Immediately after the worker bit the glove in preparation to sting, a sting dummy held with a hemostat was inserted between it and the glove with the ant's head inside one of the notches. Each worker was then allowed to sting its dummy 2-6 times, penetrating the silicone 'skin' and depositing venom onto the $\mathrm{pH}$ paper below. The alkaline venom immediately caused the paper to change color resulting in blots proportional in area to the volume of venom delivered. Each worker and its sting dummy (silicone layer removed) were then collected into separate individually marked vials. The number of stings each dummy received was recorded and the dummies were stored at $30^{\circ} \mathrm{C}$. Twenty-four hours later ( $\pm 30 \mathrm{~min}$ ) each sting dummy was video-imaged using a COHU solid-state video recording camera, and their venom blot areas were measured $\left(\mathrm{mm}^{2}\right)$ using SigmaScan Pro 4 software (Jandel Scientific Software).

\subsubsection{Effect of venom availability}

To investigate whether there is a relationship between the amount of venom workers contain and venom dose, 6 major and 6 minor workers were sting-sampled from the nest peripheries of each of 10 colonies (new gloves were used at each colony). These workers were freeze-killed in the lab and the venom sac from each was removed and ruptured onto a piece of $\mathrm{pH}$ paper. These sac blots were imaged and measured as above. The headwidth of each worker was also measured. Because the relationship between venom blot area and volume was not linear, prior to statistical analysis, blot areas in this particular study were converted to nanoliters using the calibration curve in Fig. 2 to avoid inflating the measures of total venom. For each individual worker, venom dose was calculated as the average of its sampled stings (average area converted to $\mathrm{nl}$ ), and its total venom as the sum of its converted stings and remaining venom-sac contents.

\subsubsection{Effect of age and size}

To investigate whether worker age and/or size affect venom dose, five major and five minor workers were stingsampled from each of three locations in or around five different nests. Because workers tend to move away from the brood pile as they age (Mirenda and Vinson, 1981), location was used as a proxy for worker age. Foraging ants, representing the oldest workers, were collected from dead tenebrionid beetle larvae (Zophobus sp.) placed approximately $6 \mathrm{ft}$ from the nest domes. Ants from the nest periphery, representing mid-age workers, were collected from the nest dome exterior as they emerged in response to blowing/tapping at the nest entrance. Ants from the brood 


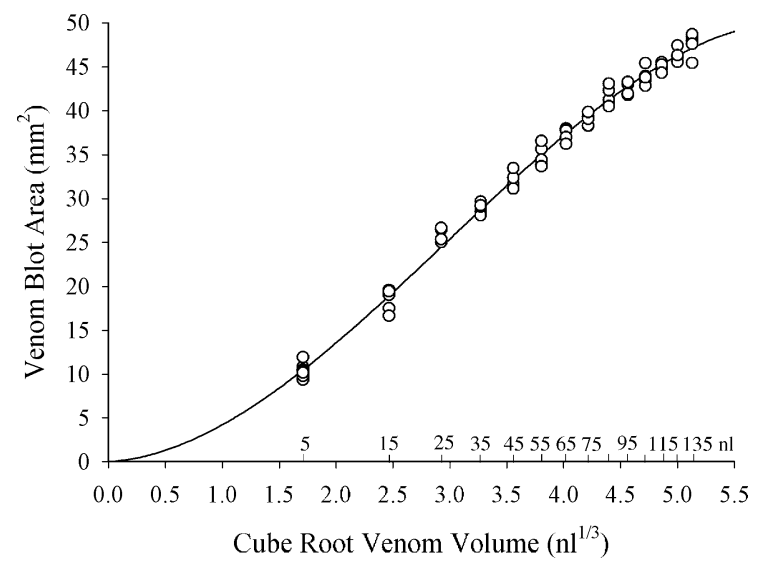

Fig. 2. Calibration curve used to convert venom blot areas to corresponding venom volumes. The equation, $\mathrm{mm}^{2}=-0.4315 \times$ $\left(\mathrm{nl}^{1 / 3}\right)^{3}+3.8492 \times\left(\mathrm{nl}^{1 / 3}\right)^{2}+0.7992 \times\left(\mathrm{nl}^{1 / 3}\right), R^{2}=0.994$, was the simplest fit through the origin that satisfied a lack-of-fit F-test $\left(F_{10,61}=1.75, P>0.20\right)$ (Ramsey and Schafer, 1997). $N=75$. Venom to construct this curve was obtained by milking hundreds of variously-sized S. invicta workers as per Rhoades (1977).

chambers, representing the youngest workers, were collected by excavation. Workers were temporarily held in Fluon-coated pans from which individuals were haphazardly selected for sting sampling. This was done to avoid confounding the effects of context (i.e. defending the nest versus defending food) with the effects of age. New gloves were used to sample workers from each age group in all colonies. Workers were freeze-killed and their headwidths were measured.

\subsubsection{Effect of season and size}

To investigate whether season and/or size affect venom dose, 5 major and 5 minor workers were stingsampled from each of the same 10 colonies on the 15 th of July, October, January, and April (Summer and Fall 2000, Winter and Spring 2001, respectively). New gloves were used to sample each colony each season. The order of colony sampling was the same every season so individual colonies were sampled at roughly the same time of day each season. Workers were freeze-killed and their headwidths were measured.

\subsection{Additional calculations}

Venom-sac-content data from unmilked workers aged 29-99 days, the venom availability study, and a supplementary 90 workers from the field were combined in order to assess the average amount of venom S. invicta workers contain. Data were converted to $\mu \mathrm{g}$ using the density of $S$. invicta venom ${ }^{2}$. Average venom-sac content

\footnotetext{
${ }^{2}$ Density was estimated to be $0.85 \mathrm{~g} / \mathrm{ml}$ by quantifying the mass $(\mu \mathrm{g})$ of venom using gas chromatography (see Haight, 2002). The estimate concurs with the report of Blum et al. (1958) that fire ant venom is less dense than water.
}

was then used to estimate (1) the energetic cost of venom and its proportion of the cost of a worker, (2) the total amount of venom in a colony, and (3) the total amount of venom a colony generates during an average 7-year lifetime (Tschinkel, 1987). Worker production cost was calculated using the average sizes of major and minor workers from this study $(1.73$ and $0.34 \mathrm{mg})$ and their respective caloric contents (7.09 and $6.66 \mathrm{cal} / \mathrm{mg}$ ) (Calabi and Porter, 1989). Venom production cost was calculated using the combined heat of combustion estimates for $\mathrm{C}_{6} \mathrm{H}_{7} \mathrm{~N}$ and $\mathrm{C}_{15} \mathrm{H}_{32}$ $(13,400 \mathrm{~kJ} / \mathrm{mole})$, and the molecular weight $(307 \mathrm{~g} / \mathrm{mole})$ of $\mathrm{C}_{21} \mathrm{H}_{41} \mathrm{~N}$, a.k.a. 2-methyl-6-(cis-6-pentadecenyl)piperidine $\left(\mathrm{C}_{15: 1}\right)$, the most abundant of $S$. invicta's six venom alkaloids (MacConnell et al., 1971; Brand et al., 1972; Glancey et al., 1980; Deslippe and Guo, 2000). Total colony output of workers (over 7 years) was calculated using Tschinkel's (1988) equation $N_{\mathrm{t}}=220,000 /\left(1+83 \mathrm{e}^{-1.26 t}\right)$, and Tschinkel and Porter's (1988) estimate of $350 \%$ yearly worker turnover in mature colonies (those over 4 years of age). Furthermore, sting-assay data from all three venomuse studies were combined to determine overall average worker venom dose. The number of average doses a worker contains and the proportion of a worker's total venom store that one average dose represents were also calculated.

\subsection{Statistical analyses}

Parametric analyses were used where transformation successfully met the requisite assumptions. Where necessary, alpha levels were adjusted to maintain a 0.05 familywise error rate. Unless otherwise noted, sting-sample data (average venom blot area from each worker, natural-log transformed) were analyzed using mixed-model nested ANOVAs. Because of the nature of this type of analysis, it was necessary to test the effect of season over the season $*$ colony mean square instead of the usual error mean square because the season $*$ colony term was significant (Winer et al., 1962). It was hypothesized a priori that if seasonal variation occurred venom dose would be greatest in the spring, the time when colonies produce large numbers of vulnerable and valuable reproductives (Morrill, 1974; Tschinkel, 1993). An a priori comparison (Sokal and Rohlf, 1995) was used to assess whether venom dose in the spring was greater than that in the rest of the year. Other, unplanned comparisons within ANOVAs were made using Tukey's Honestly Significant Difference method (HSD).

\section{Results}

\subsection{Venom-synthesis experiment}

Venom-sac content of $S$. invicta workers varied significantly with age (Fig. 3; $H=108.94$, DF $=7, P<0.001$, Kruskal-Wallis test). Workers eclosed containing very little 


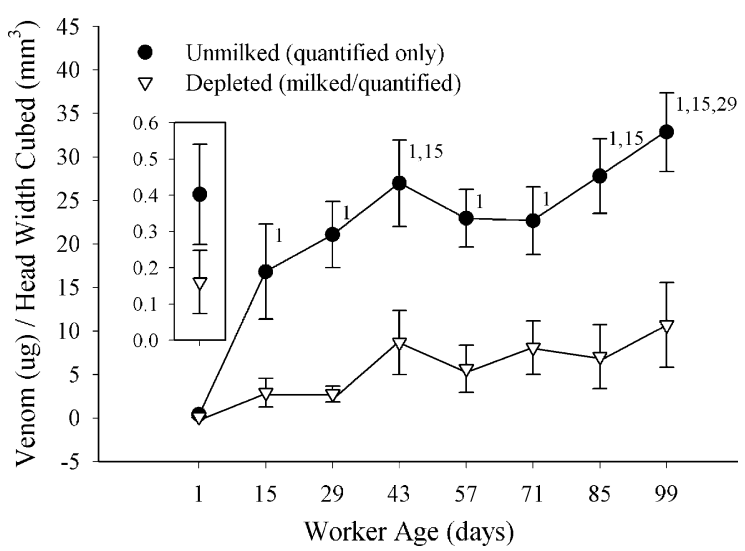

Fig. 3. Average size-standardized venom content of unmilked and depleted workers by age (with $95 \%$ confidence intervals). Among the unmilked groups annotated means are significantly different from those of the age(s) indicated (Kruskal-Wallis test followed by Dunn's test, familywise $\alpha=0.05$ ). Within age groups, depleted workers contained significantly less venom per size unit than unmilked workers did (onetailed Mann-Whitney tests, $H_{0}$ : Depleted $=$ Unmilked vs. $H_{\mathrm{A}}$ : Depleted $<$ Unmilked, maximum $p=0.0018$, familywise $\alpha=0.05$ ). Inset provided for resolution of 1dayold groups. From $\mathrm{L}$ to R: unmilked $n=30,30,45,34,38,31$, 32, and 37; depleted $n=30,30,45,35,37,28,17$, and 12 .

venom (only $0.40 \mu \mathrm{g} / \mathrm{mm}^{3}$ on average), indicating that preeclosion venom production is negligible. By 29 days of age venom-sac content had increased to a rough plateau of $25.7 \mu \mathrm{g} / \mathrm{mm}^{3}$ (average), approximately 65 -fold that of newly-eclosed workers. Milking removed $60-87 \%$ of the venom in the depleted subgroups of all ages (average $=72.4 \pm 9.2 \%$; Fig. 3 ). Within each age group, a difference between the venom content of the depleted and corresponding synthesis subgroup represents de novo synthesis. Such synthesis occurred only in the 1 and 15-day-old groups (Fig. 4; 1 day: $U=476.0, P<0.001$; 15 days: $U=657.0, P=0.003$, Mann-Whitney tests). Synthesis rates averaged $0.42 \mu \mathrm{g} / \mathrm{mm}^{3} /$ day in 1-day-old workers and $0.15 \mu \mathrm{g} / \mathrm{mm}^{3} /$ day in 15 -day-old workers. These rates were lower than those calculated ${ }^{3}$ from workers in the unmilked subgroups; 1.17 and $0.30 \mu \mathrm{g} / \mathrm{mm}^{3} /$ day in the 1 and 15-day-old groups, respectively. S. invicta venom synthesis appears then to be temporally limited, with peak synthesis rate directly after eclosion.

\subsection{Venom-use study: effect of venom availability}

Venom dose was not related to the amount of venom workers had available (Fig. 5; $r_{\mathrm{s}}=0.104, n=100$,

\footnotetext{
${ }^{3}$ Rates for unmilked workers were calculated as $\left(X_{\text {age }+1}-X_{\text {age }}\right) / t$, where $X_{\text {age }}$ is venom in focal age group, $X_{\text {age }+1}$ is venom in the next oldest age group, and $t$ is the intervening time in days $(t=14)$. Rates for milked workers were calculated as the difference between the focal age group's synthesis and depleted worker subgroups divided by the intervening time in days $(t=12)$.
}

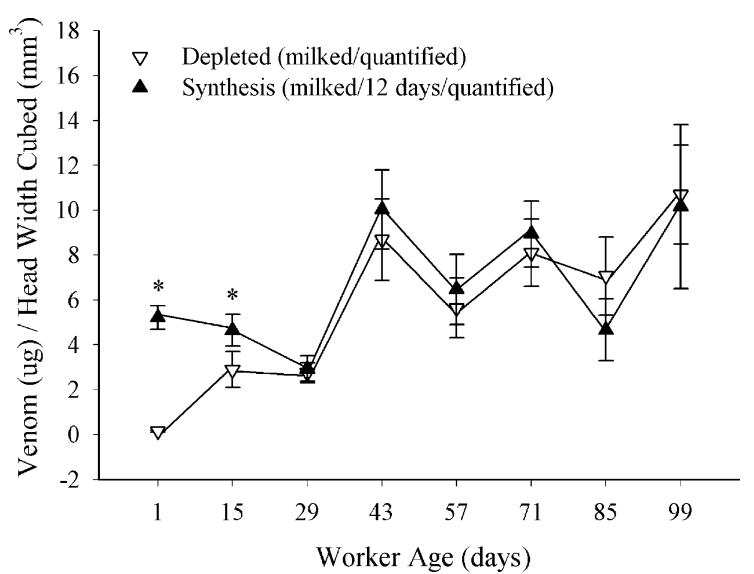

Fig. 4. Venom synthesis: average size standardized venom content of depleted and synthesis workers by age (with standard error bars). Asterisks denote those ages where significant venom synthesis occurred (one-tailed Mann-Whitney tests, $H_{0}$ : Depleted = Synthesis vs. $H_{\mathrm{A}}$ : Depleted $<$ Synthesis, family-wise $\alpha=0.05$ ). From $\mathrm{L}$ to $\mathrm{R}$ : depleted $n=30,30,45,35,37,28,17$, and 12; synthesis $n=30,23,52,42,33,31,20$, and 10 .

$P>0.20$, Spearman Rank test). However, whereas 95\% of workers delivered less than $4 \mathrm{nl}$, six exceptional workers delivered between 4 and $11 \mathrm{nl}$, about 7-18 times the average amount.

\subsection{Venom-use study: effect of age and size}

Venom dose varied significantly with worker age $\left(F_{2,120}=3.88, P=0.023\right.$, ANOVA $)$ and colony $\left(F_{4,120}=\right.$ $4.47, P=0.002)$, but not with size caste $\left(F_{5,120}=0.57\right.$, $P=0.721)$, nor were there any significant interactions.

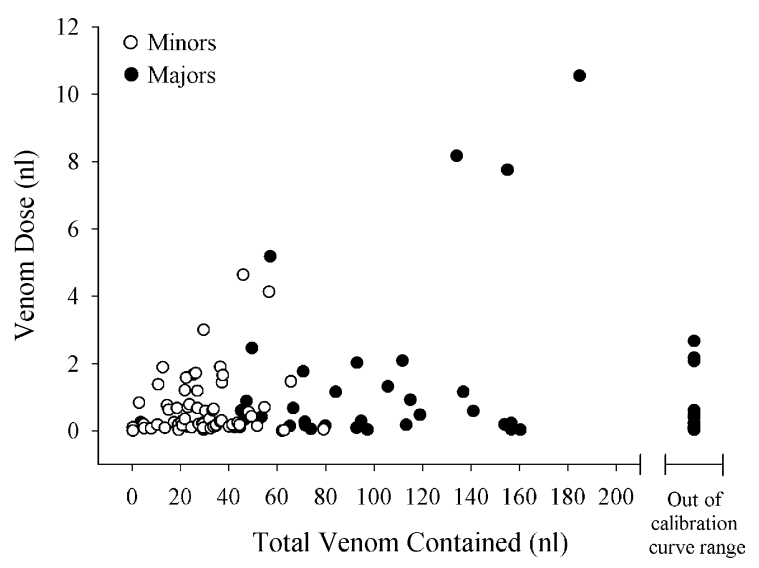

Fig. 5. Venom dose versus venom contained. Only 100/120 workers sampled were included in the analysis because 20 sac blots were outside the range of the calibration curve (Fig. 2) making it impossible to calculate the total venom available for those ants. The doses delivered by those 20 are included at the far right for comparison. Minor headwidth: mean $=0.7 \mathrm{~mm}$, range $0.60-$ $0.90 \mathrm{~mm}$. Major headwidth: mean $=1.2 \mathrm{~mm}$, range $1.00-1.35 \mathrm{~mm}$. 


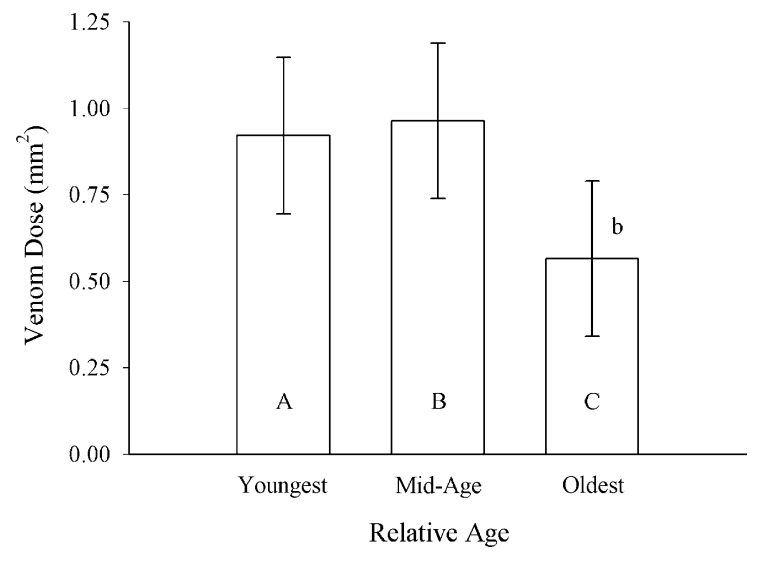

Fig. 6. Average venom doses delivered by workers of three relative ages (natural log scale with 95\% confidence intervals). Bar mean with lowercase annotation is significantly different from that of the corresponding uppercase letter (ANOVA followed by Tukey's HSD test, family-wise $\alpha=0.05) . N=50$ for each group. Venom doses reported in text are raw data averages $\left(\mathrm{mm}^{2}\right)$ converted to $\mathrm{nl}$ (see Fig. 2).

The oldest workers delivered significantly less venom per sting than the mid-age workers $(0.37$ vs. $0.72 \mathrm{nl} ; P<0.05$, Tukey's HSD; Fig. 6).

\subsection{Venom-use study: effect of season and size}

Venom dose varied significantly with season $\left(F_{3,27}=3.87, P<0.05\right.$, ANOVA $)$ and colony $\left(F_{9,300}\right.$ $=3.63, P<0.001)$, but again not with size caste $\left(F_{10,300}=1.85, p>0.10\right)$. S. invicta nest defenders delivered significantly greater venom doses in the spring than in the fall and winter $\left(F_{1,27}=4.37, P<0.05\right.$, a priori comparison; Fig. 7; spring data were compared to those of

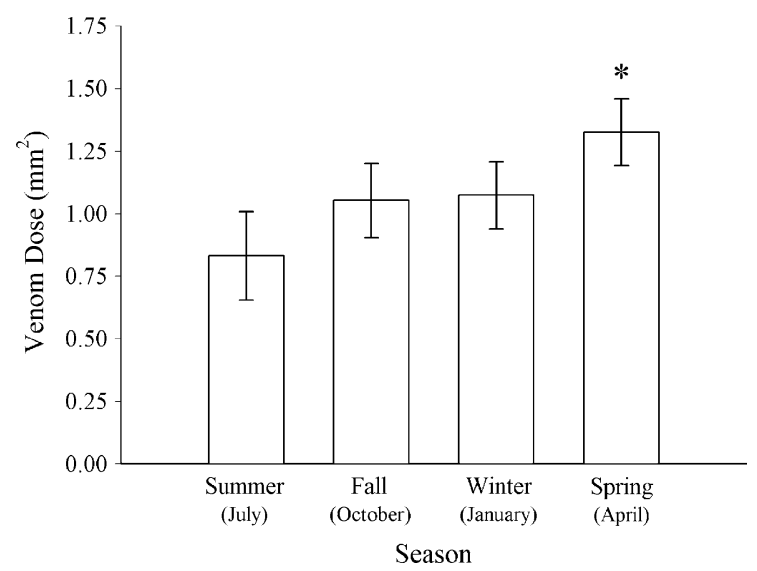

Fig. 7. Average venom dose delivered by nest-defending workers each season (natural $\log$ scale with $95 \%$ confidence intervals). Bar mean with asterisk is significantly greater than the others (ANOVA followed by a priori comparison of spring vs. fall and winter, $\alpha=0.05$ ). $N=100$ for each season. Venom doses reported in text are raw data averages $\left(\mathrm{mm}^{2}\right)$ converted to $\mathrm{nl}$ (see Fig. 2).

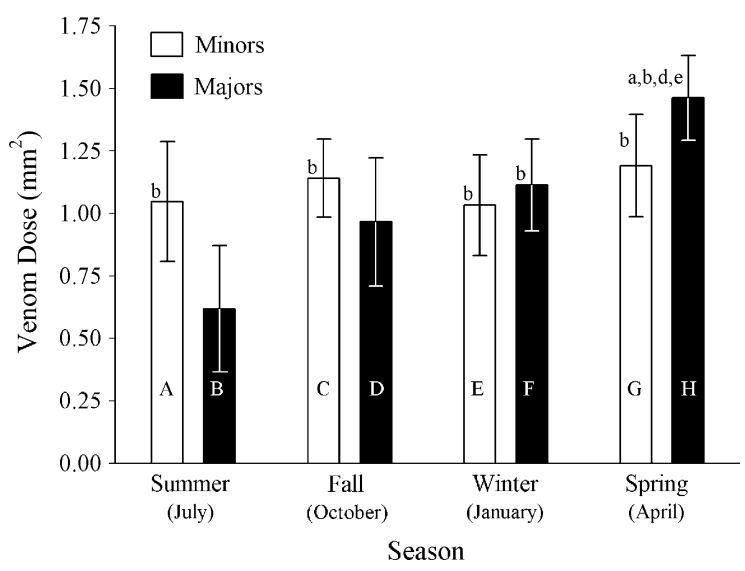

Fig. 8. Average venom doses delivered by nest-defending minors and majors each season (natural log scale with $95 \%$ confidence intervals). Bar means with lowercase annotation are significantly different from those of the corresponding uppercase letter (ANOVA followed by Tukey's HSD test, family-wise $\alpha=0.05$ ). $N=50$ for each group. Venom doses reported in text are raw data averages $\left(\mathrm{mm}^{2}\right)$ converted to $\mathrm{nl}$ (see Fig. 2). Minor headwidth: mean $=0.7$ $\mathrm{mm}$, range $0.60-0.88 \mathrm{~mm}$. Major headwidth: mean $=1.2 \mathrm{~mm}$, range $0.90-1.40 \mathrm{~mm}$.

fall and winter only, to provide a more conservative test). Venom dose was more than $55 \%$ greater in the spring $(1.15 \mathrm{nl})$ than in the rest of the year $(0.74 \mathrm{nl}$, average of summer, fall, and winter). However, not every colony responded in the same way to season, giving rise to a significant season by colony interaction $\left(F_{26,300}=2.29\right.$, $P<0.002$, ANOVA). Nonetheless, across colonies, venom dose was highest in the spring more often than in any other season. Workers also responded differently to the effects of season depending on size caste, resulting in a significant season by size caste interaction $\left(F_{30,300}=1.77\right.$, $P<0.02$, ANOVA; Fig. 8). Minors delivered consistent venom doses across season ( $0.83 \mathrm{nl}$ average) while majors delivered doses in the spring 2.7 times those they did in the summer (1.35 vs. $0.50 \mathrm{nl})(P<0.05$, Tukey's HSD).

\subsection{Additional calculations}

The overall average amount of venom contained per worker was $18.1 \mu \mathrm{g}(n=407)$. This quantity agrees with the reports of Storey et al. (1991) and Obin and Vander Meer (1985) that $S$. invicta workers contain between 10 and $20 \mu \mathrm{g}$ of venom. Less than $6 \%$ of the energy required to produce a worker was allocated to venom production (majors: $35.3 \mu \mathrm{g}$ venom average $=0.369 \mathrm{cal}$ venom, $0.369 \mathrm{cal} /$ $12.27 \mathrm{cal}=3 \%$; Minors: $11.9 \mu \mathrm{g}$ venom $=0.124 \mathrm{cal}$ venom, $0.124 \mathrm{cal} / 2.26 \mathrm{cal}=5.5 \%$ ). Assuming a standing population of 160,000 workers, $35 \%$ of whom are majors (Tschinkel, 1988), an average mature S. invicta colony contains roughly $3.2 \mathrm{~g}$ of venom. With 2.4 million workers produced during an average colony's 7-year life span, 
a grand total of roughly $43 \mathrm{~g}$ of venom is generated, representing $2.2 \%$ of an approximate total $2 \mathrm{~kg}$ of ants.

The overall average venom dose was $0.56 \mu \mathrm{g}(0.66 \mathrm{nl}$; $n=670$ ). Thus, a typical worker contains around 32 average venom doses, each of which represents $3.1 \%$ of her total venom supply. At the initial venom synthesis rate of $1.17 \mu \mathrm{g} / \mathrm{mm}^{3} /$ day, it takes a worker with a headwidth of $1 \mathrm{~mm}$ about $11.5 \mathrm{~h}$ after eclosion to generate one average venom dose $(0.56 \mu \mathrm{g})$.

\section{Discussion}

After finding a hump-shaped venom abundance distribution across age, Deslippe and Guo (2000) concluded that young and old S. invicta workers produced less venom than did workers of intermediate age. However, this distribution pattern is an ambiguous indicator of venom production because it would also occur if synthesis ability were ageconstant but young and old workers used relatively more venom. This scenario is plausible because younger workers apply venom as an antiseptic during brood care (Obin and Vander Meer, 1985) and older workers use it to acquire prey as they forage (Hays and Hays, 1959; Blum and Callahan, 1960; Vinson and Sorenson, 1986; Lockley, 1995). Because reserves (mid-age workers) probably use venom less routinely, deploying it in relatively rare nest defense, younger and older workers may be left with comparatively less venom, resulting in a hump-shaped venom abundance distribution.

Through direct measurement, we did indeed find venom synthesis to be age-dependent, but limited only to a worker's early life. Peak venom synthesis rate occurred between 1 and 15 days post-eclosion, and by 29 days of age, synthesis was undetectable (Fig. 4). Synthesis of the quinonic defensive secretion of the tenebrionid beetle, Zophobas atratus, is also limited to the young adult period (Hill and Tschinkel, 1985). A similar pattern has also been found in workers of the honey bee Apis mellifera $\mathrm{L}$.; venom synthesis activity peaks within 14 days post-eclosion (Bachmayer et al., 1972; Owen and Pfaff, 1995), and the ability to replace spent venom begins a decline to virtually nil starting around 15 days of age (Owen, 1978). The venom gland begins to degenerate at about this age (Owen and Bridges, 1976). Such limitation of secretion to early adult life may be widespread, but the data are currently too few to reveal a pattern.

While the ability to produce venom appears limited to early life, the ability to store it is undiminished by age. We found venom-sac content to be fairly constant starting around 29 days (Fig. 3). This consistency, in contrast to the drop observed by Deslippe and Guo (2000), might be due to the artificial isolation of our worker groups from live prey, competitors, and brood, reducing the stimuli that would have lead to venom depletion. Additionally, the less than
$20 \%$ of workers that survived to reach the oldest ages may have been, because of their physiological robustness, the best venom producers. This may account for the up-tick in venom-sac content of the two oldest age groups (Fig. 3).

During the venom synthesis experiment there was a curious discrepancy between the synthesis rates of milked and unmilked workers. In the two age groups that showed de novo synthesis ( 1 and 15 days), milked workers had rates that were 64 and 50\% lower than those of the corresponding unmilked workers. It would appear, then, that milking had a detrimental effect on synthesis ability. It is possible that the stress of milking ( 5 min of near continuous struggle against entrapment and exposure to a heterospecific threat), and/or invisible physical damage during milking, may have triggered physiological changes that affected venom synthesis. No matter how rate is calculated, however, the experimental evidence indicates that the majority of a worker's lifetime supply of venom is manufactured within the first 30 days of its adult life. Workers can live 70-250 days or more, depending on their size and environment (Calabi and Porter, 1989).

The converse of venom synthesis, venom-use, has been quantified in but a single previous study of $S$. invicta workers. In their investigation of 'gaster flagging', Obin and Vander Meer (1985) found S. invicta workers topically dispersed between 1 and $500 \mathrm{ng}$ of venom. This venom dispersal behavior can be observed among workers both within the nest as they tend brood and outside the nest during confrontations with heterospecific arthropods (Bhatkar et al., 1972; Obin and Vander Meer, 1985). Surprisingly, considering the frequency with which people in infested areas get stung, no study to date has quantified the dose injected. However, several authors have cited the work of Brand et al. (1973), stating that fire ant workers inject between 0.007 and $0.11 \mu \mathrm{l}$ when they sting (Rhoades, 1977; Fox et al., 1982; Stablein and Lockey, 1987), whereas we measured venom doses averaging much less (0.00037$0.00135 \mu 1)$. It is likely these authors were misled by the terminology of Brand et al. (1973) who called the venom obtained by forcibly milking $S$. geminata Fabricius workers 'sting volume'. This quantity is a more accurate reflection of the amount of venom workers contain than the amount they inject per sting, which differ because fire ants do not deliver all their venom, even when milked 'dry' (Blum and Callahan, 1960; Pers. Obs.).

Although venom production makes up less than $6 \%$ of the overall energetic cost of producing a worker, venom is apparently expensive and important enough that its use-rate is regulated. Obin and Vander Meer (1985) noted that workers dispersed lower quantities of venom during gaster flagging while tending brood than they did confronting heterospecific arthropods. Such context-dependent venomuse allows a balance between the costs of spending venom and the benefit of its effects. Such trade-offs may explain the age- and season-based patterns of venom-use observed in our study. 
We found older workers delivered lower venom doses than mid-age workers (Fig. 6). Because older workers are unable to synthesize appreciable amounts of venom, smaller venom doses potentially extend their effective careers as foragers and resource defenders by slowing the depletion of their limited venom supplies. The observed dose reduction between mid-age and older workers results in a $50 \%$ venom savings, buying a typical older worker an extra 29 stings worth of venom (mid-age: $18.1 \mu \mathrm{g} / 0.62 \mu \mathrm{g} / \mathrm{sting}=29$ stings vs. older: $18.1 \mu \mathrm{g} / 0.31 \mu \mathrm{g}=58$ ).

Because older workers are predominantly away from the nest foraging, their reduced venom doses do not weaken nest defense. The only apparent cost of their smaller venom doses is a reduction in the strength of defense against vertebrate interference at food sources. However, considering S. invicta's generalist diet (Wilson and Oliver, 1969; Vogt et al., 2002), the cost of occasionally being driven from food finds by vertebrates is not likely to be high, and is likely to be outweighed by the benefits of career-extension for foragers who more commonly encounter arthropod competitors (which, due to their size, likely require lower doses than vertebrates to dispatch).

While the effect of dose reduction is venom conservation, there is nonetheless no evidence to suggest venom conservation per se is the impetus for the reduction; workers with low reserves did not deliver lower doses (Fig. 5). However, these workers were sampled from their nest peripheries. Such workers, defenders of the nest and perhaps young enough (Mirenda and Vinson, 1981) to replace spent venom, are probably under less pressure to conserve venom than are older, foraging workers. Evidence suggesting active venom conservation (a positive relationship between venom dose and the amount of venom workers contain) is thus more likely to be found in workers older than the ones we assayed. Further investigation of the relationship between venom dose and venom reserve, using foragers (older workers), is planned.

We also found venom dose to vary seasonally (Fig. 7); dose was more than $55 \%$ greater in the spring than in the rest of the year. This increase coincides with the production of large numbers of sexuals, the reproductive castes that leave the nest to attempt founding new colonies (Morrill, 1974; Tschinkel, 1993). As these sexuals may represent as much as $50 \%$ of a colony's total energy output during the spring (Tschinkel, 1993), and represent a direct measure of colony fitness, they are extremely valuable. As concentrated stores of fat and protein, they are also attractive to predators. Failure to repel threats from the nest quickly and decisively during the spring could result in the loss or reduction of a year's worth of reproductive effort. Since pain and cell/ tissue damage are dose-dependent (Read et al., 1978), using higher venom doses should repel offending organisms more quickly and effectively. Thus, greater spring venom doses may represent an increased investment in protecting these valuable sexuals. Though we did not directly explore the effects of sexual-presence on venom dose, Judd (1998) reported that colony aggression in the wasp Polistes fuscatus was positively correlated with the number of sexual brood in the nest.

The cost of increased investment in springtime colony defense is likely to be far outweighed by the benefit to colony fitness. Indeed, the use of venom for defense of sexuals appears to be extremely efficient. One average spring venom dose of $0.98 \mu \mathrm{g}(1.15 \mathrm{nl})$ costs about $0.010 \mathrm{cal}$. The energy investment in a single female sexual is between 19 and $56 \mathrm{cal}$ (78.8 and $234 \mathrm{~J}$; Tschinkel, 1993). Thus, a single sexual female represents the same caloric cost of roughly 1900-5600 spring doses (1.9-5.5 mg of venom). Therefore, S. invicta colonies must deliver more than 5600 spring doses (a severe and probably quite effective defense indeed) before it is no longer energetically worth defending a single female sexual. As colonies average roughly 4700 sexuals/colony/year (Morrill, 1974), this translates to $26.3 \times 10^{6}$ spring doses, $23 \times 10^{6}$ more such doses than an average colony even contains. So, the amount of venom S. invicta colonies would have to spend protecting sexuals before it becomes energetically favorable to discontinue defense is orders of magnitude more than an effective defense is likely to require.

Interestingly, the spring venom dose increase appears driven by major workers; minors delivered consistent venom doses across season, while majors delivered significantly higher doses in the spring than in the summer (Fig. 8). This may reflect a seasonal change in the colonylevel importance of major workers. During the summer, majors may be an especially important component of the workforce since a timely recovery of the worker population, their numbers depressed from the production of sexuals (Tschinkel, 1993), will be dependent on the rate at which sufficient resources are gathered. The ability of majors to return larger prey items (Wilson, 1978), and their greater desiccation resistance (Hood and Tschinkel, 1990), may increase their value as foragers to the colony at this time. Because they cause pain, workers engaged in defense draw attention, exposing them to retribution, which may result in their damage or loss. Lower venom doses (i.e. less pain) from majors during summer defense may decrease their risk of being targeted (fire ants attack en masse). In the spring, when nests contain sexuals, high repellency by majors may buy more future fitness, and the risk of worker loss is outweighed by the benefit of increased repellency.

Though venom dose was found to differ by size caste during the summer, averaged over the year, dose was not found to differ between majors and minors. This means that, through the year, majors and minors are equivalent to one another as defenders against vertebrate disturbance, at least insofar as venom delivery is concerned. However, the resource investment represented by major and minor workers is not equivalent. In mature colonies, majors represent two to three times as much material investment as minors (Tschinkel, 1988), and about four times as much energy investment (costs of production and maintenance) 
(Calabi and Porter, 1989). This may help explain Wilson (1978) observation that larger S. invicta workers are less likely to respond to nest disturbances than smaller ones. As majors and minors are equivalent in defensive value, but do not represent equivalent investments, it makes economic sense for the less expensive minors to be the more reactive to nest disturbance. This costs the colony nothing in terms of defense, and reduces the rate of material and energyinvestment loss they face when repelling threats from the nest. Also, because of this defensive equivalency, if a nest disturbance is so great that risking majors in large numbers is required, doing so at least maintains the per worker strength of the defense.

In addition to worker age and season, venom dose also varied significantly with colony, suggesting venom dose may be a selectable colony-level trait. Assuming some genetic basis for these differences, and provided the right selective pressure, S. invicta should be able to evolve changes in dose-rate. Other factors such as colony age, size, reproductive investment, competitors, predators, and disturbance frequency (e.g. mowing) may also contribute to colony-level venom dose variation, and merit further study.

\section{Acknowledgements}

We are grateful to Dr Joeseph Travis for help with experimental design and statistical advice, as well as to Feiming Chen of the Florida State Statistical Consulting Center (the authors are responsible for any errors of fact or interpretation). We thank Shonna Storz, Alexander Mikheyev, Jon Seal, and Chris Smith for critical discussion, and Dr Jason Mezey, Danielle Sherdan, and two anonymous reviewers for their comments on the manuscript. This research was in partial fulfillment of the requirements of the MS degree for KLH, and was supported in part by National Science Foundation Grant number DEB-9629829.

\section{References}

Adams, C.T., Lofgren, C.S., 1981. Red imported fire ants (Hymenoptera:Formicidae): frequency of sting attacks on residents of Sumter County, Georgia. J. Med. Entomol. 18, 378-382.

Adams, C.T., Lofgren, C.S., 1982. Incidence of stings or bites of the red imported fire ant (Hymenoptera:Formicidae) and other arthropods among patients at Ft Stewart, Georgia, USA. J. Med. Entomol. 19, 366-370.

Adrouny, G.A., Derbes, V.J., Jung, R.C., 1959. Isolation of a hemolytic component of fire ant venom. Science 130, 449.

Bachmayer, H., Kreil, G., Suchanek, G., 1972. Synthesis of promelittin and melittin in the venom gland of queen and worker bees: patterns observed during maturation. J. Insect. Physiol. 18, 1515-1521.

Baer, H., Liu, T.-Y., Anderson, M.C., Blum, M., Schmid, W.H., James, F.J., 1979. Protein components of fire ant venom (Solenopsis invicta). Toxicon 17, 397-405.
Bhatkar, A., Whitcomb, W.H., Buren, W.F., Callahan, P., Carlysle, T., 1972. Confrontation behavior between Lasius neoniger (Hymenoptera:Formicidae) and the imported fire ant. Environ. Entomol. 1, 274-279.

Blum, M.S., 1984. Poisonous ants and their venoms. In: Tu, T., (Ed.), Handbook of Natural Toxins-Insect Poisons, Allergens, and other Invertebrate Venoms, vol. 2. Marcel Dekker, New York, pp. 225-242.

Blum, M.S., 1988. Biocidal and deterrent activities of nitrogen heterocycles produced by venomous myrmicine ants. In: Cutler, H.G., (Ed.), Biologically Active Natural Products: Potential Use in Agriculture, American Chemical Society, Washington, DC, pp. 438-449.

Blum, M.S., Callahan, P.S., 1960. Chemical and biological properties of the venom of the imported fire ant (Solenopsis saevissima var. richteri Forel) and the isolation of the insecticidal component. Proc. 11th Int. Congr. Entomol. Vienna 3, 290-293.

Blum, M.S., Walker, R.J., Callahan, P.S., Novak, A.F., 1958. Chemical, insecticidal, and antibiotic properties of fire ant venom. Science 128, 306-307.

Brand, J.M., Blum, M.S., Barlin, M.R., 1973. Fire ant venoms: intraspecific and interspecific variation among castes and individuals. Toxicon 11,325-331.

Brand, J.M., Blum, M.S., Fales, H.M., MacConnell, J.G., 1972. Fire ant venoms: Comparative analyses of alkaloidal components. Toxicon 10, 259-271.

Calabi, P., Porter, S.D., 1989. Worker longevity in the fire ant Solenopsis invicta: ergonomic considerations of correlations between temperature, size, and metabolic rates. J. Insect Physiol. 35, 643-649.

Caro, M.R., Derbes, V.J., Jung, R., 1957. Skin responses to the sting of the imported fire ant (Solenopsis saevissima) A.M.A. Arch. Dermatol. 75, 475-488.

Clemmer, D.I., Serfling, R.E., 1975. The imported fire ant: dimensions of the urban problem. South. Med. J. 68, $1133-1138$.

deShazo, R.D., Griffing, C., Kwan, T.H., Banks, W.A., Dvorak, H.F., 1984. Dermal hypersensitivity reactions to imported fire ants. J. Allergy Clin. Immunol. 74, 841-847.

Deslippe, R.J., Guo, Y.-J., 2000. Venom alkaloids of fire ants in relation to worker size and age. Toxicon 38, 223-232.

Fox, R.W., Lockey, R.F., Bukantz, S.C., 1982. Neurologic sequelae following the imported fire ant sting. J. Allergy Clin. Immunol. $70,120-124$.

Glancey, M., Glover, A., Lofgren, C.F., 1980. Observations of intercastes in Solenopsis invicta Buren. Fla. Ent. 63, 346-350.

Haight, K.L., 2002. Fire ant venom economy: patterns of synthesis and use. MS Thesis, Department of Biological Science, Florida State University, Tallahassee, FL.

Hays, S.B., Hays, K.L., 1959. Food habits of Solenopsis saevissima richteri Forel. J. Econ. Entomol. 52, 455-457.

Hill, C.S., Tschinkel, W.R., 1985. Defensive secretion production in the tenebrionid beetle, Zophobas atratus: Effects of age, sex, and milking frequency. J. Chem. Ecol. 11, 1083-1092.

Hood, G.W., Tschinkel, W.R., 1990. Desiccation resistance in arboreal and terrestrial ants. Physiol. Entomol. 15, 23-35.

Jouvenaz, D.P., Blum, M.S., MacConnell, J.G., 1972. Antibacterial activity of venom alkaloids from the imported fire ant, Solenopsis invicta Buren. Antimicrob. Agents Chemother. 2, 291-293. 
Judd, T.M., 1998. Defensive behavior of colonies of the paper wasp, Polistes fuscatus, against vertebrate predators over the colony cycle. Insectes Soc. 45, 197-208.

Jung, R.C., Derbes, V.J., Burch, A.D., 1963. Skin response to solenamine, a hemoloytic component of fire-ant venom. Dermatol. Tropica 2, 241-244.

Lamon, B., Topoff, H., 1985. Social facilitation of eclosion in the fire ant, Solenopsis invicta. Dev. Psychobio. 18, 367-374.

Leclercq, S., Braekman, D., Daloze, D., Pasteels, J.M., Vander Meer, R.K., 1996. Biosynthesis of the solenopsins, venom alkaloids of the fire ant. Naturwissenschaften 83, 222-225.

Lind, N.K., 1982. Mechanism of action of fire ant (Solenopsis) venoms, I. Lytic release of histamine from mast cells. Toxicon 20, 831-840.

Lockley, T.C., 1995. Effect of imported fire ant predation on a population of the least tern-an endangered species. S. W. Entomol. 20, 517-519.

MacConnell, J.G., Blum, M.S., Fales, H.M., 1971. The chemistry of fire ant venom. Tetrahedron 26, 1129-1139.

Mirenda, J.T., Vinson, S.B., 1981. Division of labour and specification of castes in the red imported fire ant Solenopsis invicta Buren. Anim. Behav. 29, 410-420.

Morrill, W.L., 1974. Production and flight of alate red imported fire ants. Environ. Entomol. 3, 265-271.

Obin, M.S., Vander Meer, R.K., 1985. Gaster flagging by fire ants (Solenopsis spp.): functional significance of venom dispersal behavior. J. Chem. Ecol. 11, 1757-1768.

Owen, M.D., 1978. Venom replenishment, as indicated by histamine, in honey bee (Apis mellifera) venom. J. Insect Physiol. 24, 433-437.

Owen, M.D., Bridges, A.R., 1976. Aging in the venom glands of queen and worker honey bees (Apis mellifera L): some morphological and chemical observations. Toxicon 14, 1-5.

Owen, M.D., Pfaff, L.A., 1995. Melittin synthesis in the venom system of the honey bee (Apis mellifera L.). Toxicon 33, 1181-1188.

Porter, S.D., 1983. Fast, accurate method of measuring ant head widths. Ann. Entomol. Soc. Am. 76, 866-867.

Porter, S.D., Tschinkel, W.R., 1985. Fire ant polymorphism: the ergonomics of brood production. Behav. Ecol. Sociobiol. 16, 323-336.

Ramsey, F.L., Schafer, D.W., 1997. The Statistical Sleuth: A Course in Methods of Data Analysis, Duxbury Press, New York.
Read, G.W., Lind, N.K., Oda, C.S., 1978. Histamine release by fire ant (Solenopsis) venom. Toxicon 16, 361-367.

Rhoades, R.B., 1977. Medical Aspects of the Imported Fire Ant, The University Presses of Florida, Gainesville, FL.

Rhoades, R.B., Stafford, C.T., James, F.K. Jr., 1989. Survey of fatal anaphylactic reactions to imported fire ant stings. J. Allergy Clin. Immunol. 84, 159-162.

Sokal, R.R., Rohlf, J.F., 1995. Biometry, W.H. Freeman and Company, New York.

Stablein, J.J., Lockey, R.F., 1987. Adverse reactons to ant stings. Clin. Rev. Allergy 5, 161-175.

Storey, G.K., Vander Meer, R.K., Boucias, D.G., McCoy, C.W., 1991. Effect of fire ant (Solenopsis invicta) venom alkaloids on the in vitro germination and development of selected entomogenous fungi. J. Invert. Path. 58, 88-95.

Tschinkel, W.R., 1987. Fire ant queen longevity and age: estimation by sperm depletion. Ann. Entomol. Soc. Am. 80, 263-266.

Tschinkel, W.R., 1988. Colony growth and the ontogeny of worker polymorphism in the fire ant, Solenopsis invicta. Behav. Ecol. Sociobiol. 22, 103-115.

Tschinkel, W.R., 1993. Sociometry and sociogenesis of colonies of the fire ant Solenopsis invicta during one annual cycle. Ecol. Monographs 63, 425-457.

Tschinkel, W.R., Porter, S.D., 1988. Efficiency of sperm use in queens of the fire ant, Solenopsis invicta (Hymenoptera:Formicidae). Ann. Entomol. Soc. Am. 81, 777-781.

Vander Meer, R.K., 1988. Behavioral and biochemical variation in the fire ant, Solenopsis invicta. In: Jeanne, R.L., (Ed.), Interindividual Behavioral Variability in Social Insects, Westview Press, Boulder, CO, pp. 223-255.

Vinson, S.B., Sorenson, A.A., 1986. Imported Fire Ants: Life History and Impact, Texas Department of Agriculture, Austin.

Vogt, J.T., Grantham, R.A., Corbett, E., Rice, S.A., Wright, R.E., 2002. Dietary habits of Solenopsis invicta (Hymenoptera:Formicidae) in four Oklahoma habitats. Environ. Entomol. 31, $47-53$.

Wilson, E.O., 1978. Division of labor in fire ants based on physical castes (Hymenoptera:Formicidae: Solenopsis). J. Kans. Ent. Soc. 51, 615-636.

Wilson, N.L., Oliver, A.D., 1969. Food habits of the imported fire ant in pasture and pine forest area in southern Louisiana. J. Econ. Entomol. 62, 1268-1271.

Winer, B.J., Brown, D.R., Michels, K.M., 1962. Statistical Principles in Experimental Design, McGraw-Hill, New York. 